\title{
Predictive factors for positive disco- vertebral biopsy culture in pyogenic vertebral osteomyelitis, and impact of fluoroscopic versus scanographic guidance
}

Caroline Diffre ${ }^{1}$, Camille Jousset ${ }^{1}$, Anne-Laure Roux², Clara Duran ${ }^{3}$, Latifa Noussair ${ }^{2}$, Martin Rottman², Robert-Yves Carlier ${ }^{1}$ and Aurélien Dinh $^{3^{*}}$ (D)

\begin{abstract}
Background: The aims of this study were to identify the predictive factors for microbiological diagnosis through disco-vertebral biopsy (DVB) in patients with pyogenic vertebral osteomyelitis (PVO) and negative blood cultures, and compare the performance of DVB under fluoroscopic versus scanographic guidance.

Methods: We performed a cohort study comparing positive and negative DVB among patients with PVO. All cases of PVO undergoing a DVB for microbiological diagnosis in our center were retrospectively reviewed. Infections due to Mycobacterium tuberculosis, infections on foreign device, and non-septic diseases were excluded. Anamnestic, clinical, biological, microbiological, as well as radiological data were collected from medical charts thanks to a standardized data set.

Results: A total of 111 patients were screened; 88 patients were included. Microbiological cultures were positive in $53 / 88(60.2 \%)$ patients. A thickening of the paravertebral tissue $\geq 10 \mathrm{~mm}$ on magnetic resonance imaging (MRI) in axial MR scans was a predictive factor of DVB microbiological positivity ( $52.4 \%$ vs. $13.3 \% ; p=0.006 ; O R=5.4)$. Overall, 51 DVB were performed under fluoroscopic guidance and 37 under scanographic guidance. Considering lumbar DVB, 25/36 (69.4\%) of cases yielded positive results under fluoroscopic guidance versus 5/15 (33.3\%) under scanographic guidance $(p=0.02 ; \mathrm{OR}=4.4)$. No adverse event linked to DVB was notified.

Conclusion: Every patient with PVO and negative blood cultures should undergo a DVB. A thickening of the paravertebral tissue $\geq 10 \mathrm{~mm}$ on MRI is associated with a higher rate of positive DVB culture. A lumbar DVB under fluoroscopic guidance is more sensitive than under scanographic guidance to identify the micro-organism involved.
\end{abstract}

Keywords: Vertebral osteomyelitis, Fluoroscopy, DVB, MRI, Paravertebral infiltration

\footnotetext{
* Correspondence: aurelien.dinh@aphp.fr

${ }^{3}$ Infectious disease unit, Raymond Poincaré University Hospital, AP-HP Paris Saclay University, 104, boulevard Raymond Poincaré, 92380 Garches, France Full list of author information is available at the end of the article
}

(c) The Author(s). 2020 Open Access This article is licensed under a Creative Commons Attribution 4.0 International License, which permits use, sharing, adaptation, distribution and reproduction in any medium or format, as long as you give appropriate credit to the original author(s) and the source, provide a link to the Creative Commons licence, and indicate if changes were made. The images or other third party material in this article are included in the article's Creative Commons licence, unless indicated otherwise in a credit line to the material. If material is not included in the article's Creative Commons licence and your intended use is not permitted by statutory regulation or exceeds the permitted use, you will need to obtain permission directly from the copyright holder. To view a copy of this licence, visit http://creativecommons.org/licenses/by/4.0/ The Creative Commons Public Domain Dedication waiver (http://creativecommons.org/publicdomain/zero/1.0/) applies to the data made available in this article, unless otherwise stated in a credit line to the data. 


\section{Background}

Pyogenic vertebral osteomyelitis (PVO) is an infection of the disk and the corpus of the adjacent vertebrate, which may extend to the epidural or paravertebral area. It is usually due to blood stream dissemination $(80 \%$ of cases), rather than a direct inoculation during surgery or radiological intervention, such as disco-vertebral biopsy (DVB) [1]. Staphylococcus aureus is the most frequent pathogen involved $[2,3]$.

It is a rare disease but its incidence has risen in recent years [4]. It is now estimated at 2,4 per 100, 000 habitants per year, increasing with age [2]. The lumbar level is the most frequent affected part of the spine (more than $50 \%$ of cases) compared to dorsal (30\%) and cervical spine (20\%) [5-7]. PVOs are characterized by non-specific presentation: back pain $(80 \%)$, fever $(50 \%)$, or neurological symptoms in case of complication [8]. Therefore, the diagnostic delay varies between 3 and 13 weeks $[8,9]$. Magnetic resonance imaging (MRI) is the more sensitive and specific technic for positive diagnosis. It allows to distinguish infections from degenerative diseases, such as Modic 1 inflammatory discitis or microcrystalline disease.

Identification of a causative microorganism is a key point in management of PVO. Indeed, it allows an effective and targeted antimicrobial treatment on the bacteria involved. Blood cultures may identify the causative organism in up to 40 to $60 \%$ of cases [10]. In patients with negative blood cultures, a percutaneous DVB is recommended [8].

DVB could be performed under fluoroscopic or scanographic guidance. However, guidelines do not specify which modality is preferential. In the literature, DVB are mainly performed under scanographic guidance, which may be due to an apparent safety, especially at the thoracic level due to proximity of the aorta [11-13].

The reported DVB's sensitivity is around 50\%, and vary from 30 to $91 \%$ [8, 13-17]. But, a study comparing the two types of guidance has never been performed to best of our knowledge.

The primary objective of our study was to identify the predictive factors of DVB positive cultures. The secondary objective was to compare the performance of DVB under fluoroscopic versus scanographic guidance.

\section{Methods}

\section{Study design and patients}

We performed a retrospective study of all patients who underwent DVB for PVO with negative blood cultures between January 1st, 2002 and December 31st, 2017 in a French tertiary care hospital, identified using the local register of interventional procedures.
The diagnosis of PVO was assessed by an independent committee comprised of 2 radiologists (CD1 and $\mathrm{RYC}$ ) and one infectious disease physician expert in PVO (AD) after reviewing all available radiological exams and clinical and biological data. If all members disagree on a patient's classification, the patient's data was reviewed jointly during a formal meeting to find a consensus,

No patient included in the study expressed opposition to the use of clinical data in this retrospective study. Because of its retrospective design, no institutional review board approval was needed. The study was done in accordance with the ethical principles of the Declaration of Helsinki and the Guidelines for Good Clinical Practice.

The following data were collected using a standardized record data set: technical data, i.e. guidance's modality (scopic versus fluoroscopic guidance), level of the DVB (D11-D12 was considered on thoracic level, L5-S1 on lumbar level); bacteriological data; baseline clinical data, such as age, sex, previous spine surgery without material (laminectomy, discectomy), antibiotics during the previous 21 days before DVB, disease presentation (acute: clinical-radiological diagnosis delay lower than 30 days; subacute: clinical-radiological diagnosis delay between 30 days and 6 months; chronic: clinical-radiological diagnosis delay higher than 6 months), presence or absence of fever during the 24 $\mathrm{h}$ following the DVB (defined as temperature higher than $38^{\circ} \mathrm{C}$ ); biological data; and radiological findings such as para-vertebral, discal, or psoas abscess, paravertebral infiltration more or equal to $10 \mathrm{~mm}$, vertebral endplates erosions more than $50 \%$ of the height of vertebral body, and epiduritis.

\section{DVB}

The vertebral level was defined according to pre-interventional MRI. All patients received moderate sedation using $1 \mathrm{~g}$ of paracetamol. Sedation and analgesia could secondarily be assured by medical nitrous oxide and oxygen gas mixture.

CT-guided biopsy was performed on a Somaton Definition AS plus (Siemens Healthcare SAS, Erlangen 91,052, Germany). A thin-slice planning CT scan (0.75 $\mathrm{mm}$ slice thickness) was realized in prone position and multiplanar reconstructions were used to nontraumatically position the biopsy needle.

Fluoroscopic-guided biopsy was performed on a Philips VELARA Integris ALLURA table (Philips Healthcare, Best 5684 PC, Netherlands).

Chlorhexidine-isopropylic alcohol overlying the biopsy needle trajectory and consecutive local anesthesia with $10 \mathrm{~mL}$ lidocaine 0,5\% (Aguettant, 69,007, Lyon, France) 
and then with lidocaine $0,5 \%$-chirocaine $2,5 \mathrm{mg} / \mathrm{mL}$ (Abbvie, North Chicago, USA) in touch with periostea were used for aseptic preparation of the skin.

A small skin incision was made and biopsy was performed using T'AM kit (Thiebaud Biomedical Devices, Margenciel, France) with a $13 \mathrm{G}$ biopsy system, Laredo-Bard Trocar (VM-Tech, Cachan), bone marrow biopsy needle Quick-Core (Cook, Bloomington, USA).

For DVB under fluoroscopic guidance, we used a postero-lateral approach with a patient in $3 / 4$ on the table (Fig. 1) [8]. A transpedicular, inter-costovertebral or postero-lateral approach can be chosen for DVB under scanographic guidance (Fig. 2). According to the guidelines, several bone and discal samples were realized [8].

\section{Microbiology}

Intraoperative samples obtained from DVB were processed independently. They were topped with $17 \mathrm{~mL}$ sterile distilled water and bead milled for $150 \mathrm{~s}$ on a Retsch MM400 mixer mill (Verder, France) with 10 to 155 -mm-diameter stainless steel beads. One hundred microliters of the resulting suspension was plated on 5\% sheep blood Columbia agar and chocolate agar and incubated for 5 days at $35^{\circ} \mathrm{C}$ under aerobic, anaerobic, and 5\% CO2-enriched atmospheres. Enrichment was performed in blood culture vials in 34 samples and in Schaedler's broth in 27 samples [18].
All isolates were identified by mass spectrometry (Biotyper on a Microflex LT mass spectrometer, Bruker Daltonics, Bremen, Germany) and their antimicrobial susceptibility tested by disk diffusion. Confirmation of the minimal inhibitory concentration (MIC) was performed by ellipsometry or broth microdilution (Etest, BioMérieux, Marcy l'Etoile, France or UMIC, Biocentric, Bandol, France) on available isolates and reinterpreted according to the EUCAST 2018 guidelines [19].

\section{Statistics}

Pearson chi-square test or Fisher exact test were used to compare categorical variable. For all tests, $p$ values $\leq 0.05$ were considered as statistically significant.

Quantitative variables are presented as median and interquartile range (IQR), and qualitative variables are presented as number of occurrences and relative frequencies.

Statistical analysis was performed with Statistical Package for Social Science for Windows version 17.0 (SPSS, Chicago, USA).

\section{Results}

A total of 111 medical files were reviewed, and 88 patients with clinical and morphological diagnosis of PVO, assessed by the committee, were included (Fig. 3). Out of the 23 patients excluded, exclusion criteria were: presence of osteosynthesis material $(n=9)$, infection involving Mycobacterium tuberculosis $(n=8)$, microcrystalline arthritis $(n=4)$, and neoplasia $(n=2)$.

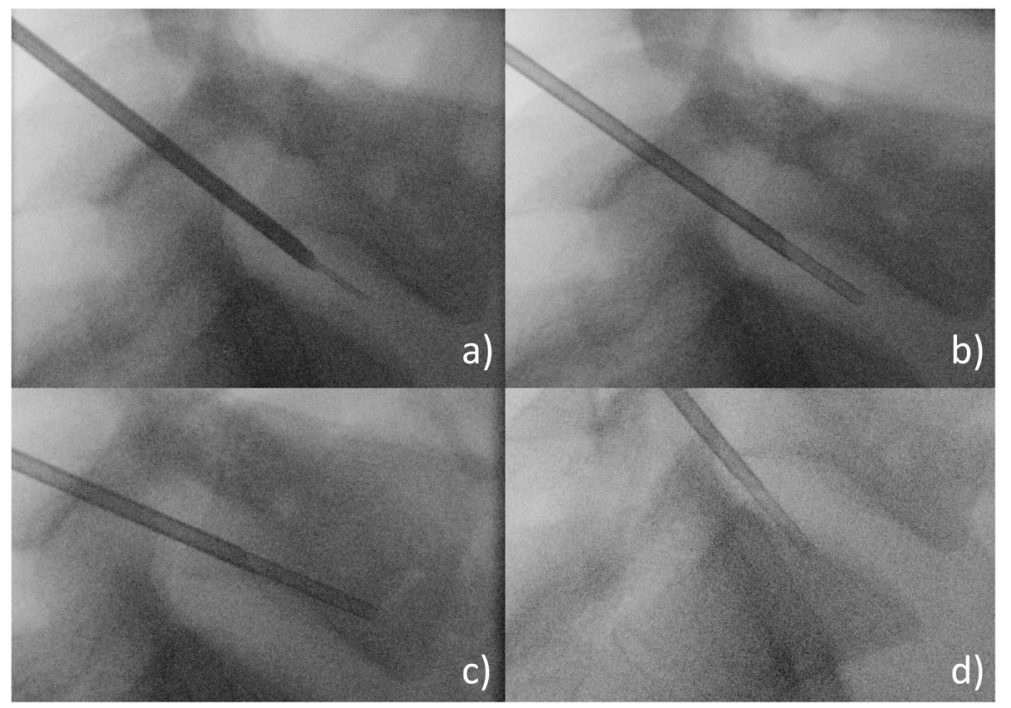

Fig. 1 Disco-vertebral biopsy (DVB) under fluoroscopic guidance at the L5-S1 level. DVB at this level needs a large craniocaudal angulation and will target the L5 lower vertebral body rather than the L5-S1 disk or S1 upper vertebral body because bone marrow yields better samples than disk, and targeting the S1 upper body is difficult due to the overlaying shadow of the iliac bones. a Trocard on the guide needle. $\mathbf{b}$ Sample of L5-S1 space. c Sample of inferior vertebral body endplate of L5. $\mathbf{d}$ Sample of superior vertebral body endplate of S1 

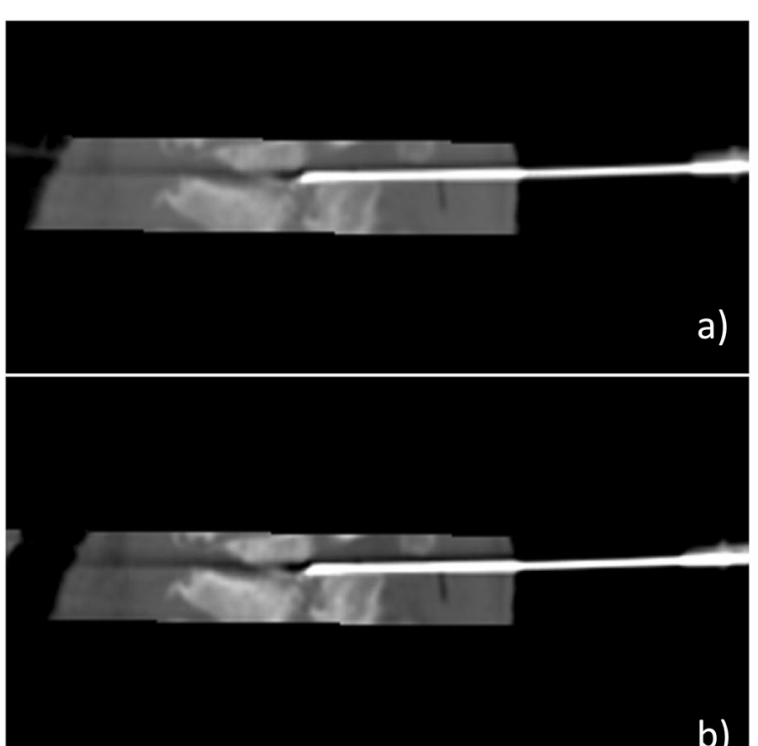

b)

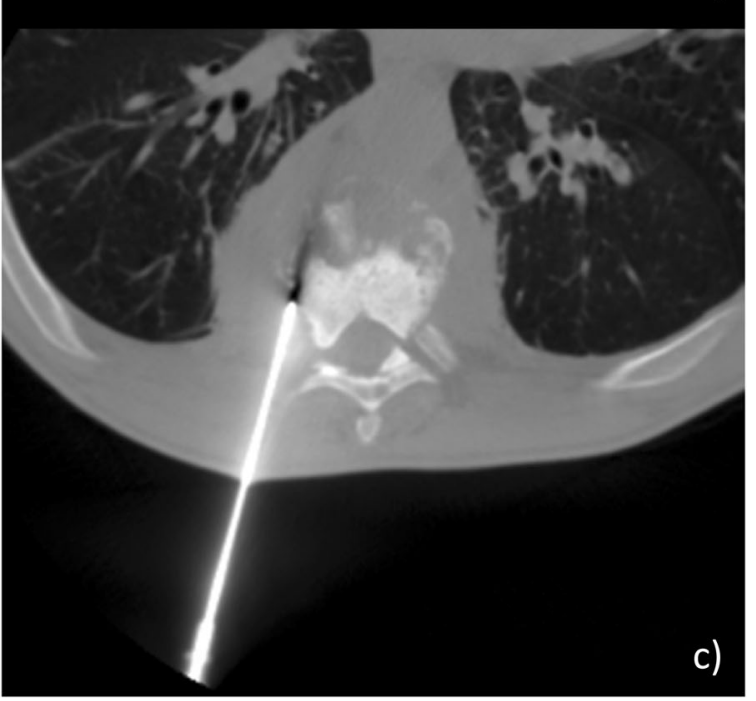

Fig. 2 DVB under scanographic guidance at T8-T9 level. a Position of the needle guide at T8-T9 disk space. b Sample of inferior vertebral endplate of T8. c Inter-costo-vertebral approach

Median age was 67.0 years, and mean age was 61.7 years (range 20-89), with a sex ratio (M/F) of 2.7 . Immunosuppression was present in $9(10.2 \%)$ patients, and half of patients $(n=42 ; 47.7 \%)$ had acute PVO presentation. Previous antibiotic treatment was notified in $19(21.6 \%)$ patients. Epidural abscess and paravertebral infiltration were reported respectively in 13 (18.3\%) and $26(36.1 \%)$. The main localization of PVO was lumbar $(n=51 ; 58.0 \%)$, and the main bacteria involved was staphylococci $(n=25 ; 47.3 \%)$.

Overall, 53 (60.2\%) patients had positive DVB cultures, whereas 35 (39.8\%) patients had negative DVB cultures (Table 1). Patients' baseline characteristics according to the DVB results are presented in Table 1.
There was no significant difference between the two groups concerning immunosuppression $(p=$ $0.76)$, previous spine surgery $(p=0.19)$, antibiotics during the previous 21 days before DVB $(p=0.2)$, disease presentation (acute vs. subacute, $p=0.26$; acute vs. chronic, $p=0.58$ ), fever during the following $24 \mathrm{~h}$ DVB $(p=0.81)$. Regarding biologic data, we found no significant difference between the two groups. But, paravertebral thickening more than 10 $\mathrm{mm}$ (in cervical, thoracic and lumbar spine) was present in 22/53 (52.4\%) cases with positive DVB vs. $4 / 35$ (13.3\%) cases with negative DVB which was significantly different $(p<0.001$; odds ratio $(\mathrm{OR})=$ 5.4, 95\% Confidence interval (CI) [1.58-24.10]). 


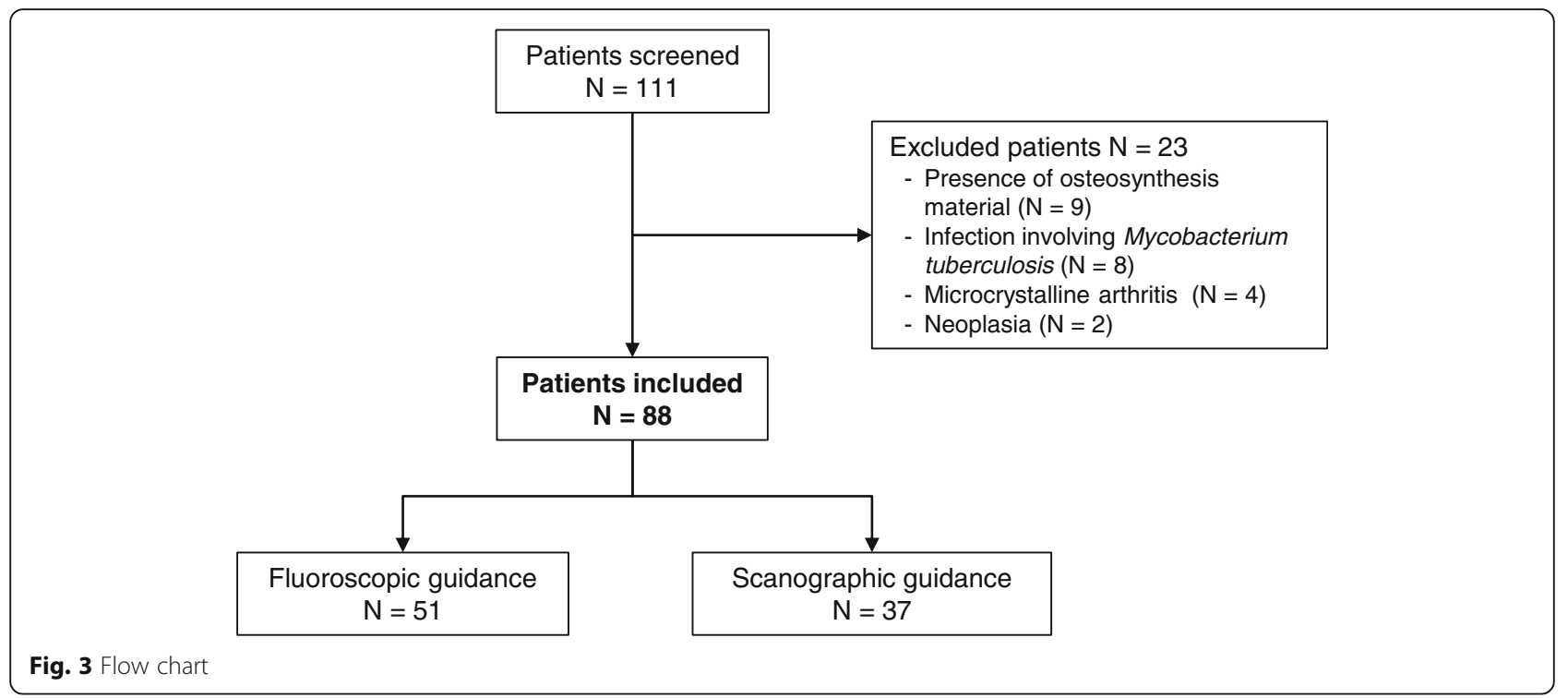

Concerning the others imaging findings, no significant difference was found.

The most frequent causative micro-organisms isolated were coagulase negative Staphylococci $(n=15,28.3 \%)$, and Staphylococcus aureus $(n=10,18.9 \%)$.

DVB was performed under fluoroscopic guidance in $51 / 88(58.0 \%)$ cases vs. $37 / 88(42.0 \%)$ cases under scanographic guidance. DVB cultures were positive under fluoroscopic guidance in 34/51 cases (66.7\%) vs. $19 / 37$ cases $(51.3 \%)$ under scanographic guidance $(p=0.15)$ (Table 2). Concerning the lumbar spine, positive rate of DVB cultures under fluoroscopic guidance was significantly different than that under scanographic guidance $(25 / 36 \quad(69.4 \%)$ vs. $5 / 15$ (33.3\%), $p=0.02$, respectively) (Table 2). Concerning DVB performed in the cervical and thoracic levels, no significant difference was shown between fluoroscopic and scanographic guidance (Table 2).

There were no biopsy-related major complications such as hemorrhage, infection, fracture or major pneumothorax.

\section{Discussion}

Our cohort study among patients with PVO with negative blood cultures who underwent DVB showed that DVB positive cultures are significantly associated with a paravertebral thickening more than $10 \mathrm{~mm}$ and DVB with fluoroscopic guidance at lumbar level. These results could help the physicians manage patients presenting an indication for DVB in case of PVO.

Our population is representative of the general population with $\mathrm{PVO}$, with the same mean age according to a recent epidemiological study [20].
The most frequently identified microorganisms were coagulase negative Staphylococci, whereas in the literature, Staphylococcus aureus is the most frequently involved [8]. It should be noted that we only included patients with negative blood culture, which explains the large number of coagulase negative staphylococci PVO. Our PVO cases were mostly monomicrobial, as previously reported [21].

According to our results, age, sex, clinical or biological characteristics were not statistically associated with a positive DVB, as reported in literature $[13,14]$. Moreover, in a retrospective study including 75 patients, Wu et al. did not show significant difference in the culture positivity rate with regard to fever $>38^{\circ} \mathrm{C}$, elevated WBC $\geq 10^{9} / \mathrm{L}$, elevated C-Reactive Protein level $\geq 6 \mathrm{mg} / \mathrm{L}$, as did we [17].

In our study, univariate analysis showed that paravertebral tissue $\geq 10 \mathrm{~mm}$ of thickening on axial MR scans is a predictive factor of microbiological positivity of DVB (Table 1). This result is in line with the retrospective study by Spira et al., which included only 34 patients who underwent DVB under scanographic guidance, and showed that a threshold of paravertebral soft tissue $>5 \mathrm{~mm}$ reliably indicated successful pathogen detection [22].

Considering type of guidance, DVB under fluoroscopic guidance at the lumbar level seems more sensitive to identify causative micro-organisms (Table 2).

It could be explained by the fact that fluoroscopic guidance allows a wide range of craniocaudal angulation, an easy perception of the needle position in the vertebral body in the lateral view, a short procedure time, and real-time visualization and control of the 
Table 1 Baseline characteristics of study patients according to the disco-vertebral biopsies (DVB) results

\begin{tabular}{|c|c|c|c|}
\hline Patients & $\begin{array}{l}\text { Positive DVB } \\
(\boldsymbol{n}=53)\end{array}$ & $\begin{array}{l}\text { Negative DVB } \\
(\boldsymbol{n}=35)\end{array}$ & $\boldsymbol{P}$-value \\
\hline Age (years), median [IQR] & $67.0[54.0 ; 80.0]$ & $63.0[47.5 ; 76.0]$ & 0.31 \\
\hline Sex ratio (M/F) & 2.5 & 2.9 & 0.79 \\
\hline Immunosuppression, n (\%) & $5(9.4)$ & $4(11.4)$ & 0.76 \\
\hline Previous spine surgery, n (\%) & $8(15.0)$ & $2(5.7)$ & 0.19 \\
\hline \multicolumn{4}{|l|}{ PVO presentation, n (\%) } \\
\hline Acute & $25(47.2)$ & $17(48.6)$ & 1.0 \\
\hline Subacute & $6(11.3)$ & $7(20.0)$ & 0.26 \\
\hline Chronic & $9(17.0)$ & $4(11.4)$ & 0.58 \\
\hline Previous antibiotic therapy, $n(\%)$ & $9(17.0)$ & $10(28.6)$ & 0.2 \\
\hline Fever, n (\%) & $2(3.8)$ & $1(2.9)$ & 0.82 \\
\hline \multicolumn{4}{|l|}{ Biology, median [IQR] } \\
\hline WBC count $\left(10^{9} / \mathrm{L}\right)$ & $9.5[7.4 ; 11.5]$ & $7.6[6.2 ; 12.2]$ & 0.44 \\
\hline CRP level (mg/L) & $47.0[26.0 ; 120.0]$ & $26.5[8.5 ; 123.5]$ & 0.42 \\
\hline ALP (UI/L) & $117.0[90.0 ; 179.5]$ & $144.0[100.0 ; 212.0]$ & 0.24 \\
\hline \multicolumn{4}{|l|}{ Biology, n (\%) } \\
\hline WBC $>10\left(10^{9} / L\right)$ & $19(47.5)$ & $10(35.7)$ & 0.33 \\
\hline $\mathrm{CRP}>50 \mathrm{mg} / \mathrm{L}$ & $19(86.4)$ & $12(42.8)$ & 0.77 \\
\hline $\mathrm{CRP}>100 \mathrm{mg} / \mathrm{L}$ & $14(34.1)$ & $8(28.6)$ & 0.62 \\
\hline ALP > $118 \mathrm{UI} / \mathrm{L}$ & $20(55.6)$ & $18(64.2)$ & 0.48 \\
\hline \multicolumn{4}{|l|}{ Radiology, n (\%) } \\
\hline Epidural abscess & $8(19.5)$ & $5(16.7)$ & 0.76 \\
\hline Psoas abscess & $7(17.1)$ & $8(26.7)$ & 0.33 \\
\hline Discal abscess & $11(26.2)$ & $8(26.7)$ & 0.96 \\
\hline Paravertebral abscess & $12(29.3)$ & $9(30.0)$ & 0.95 \\
\hline Vertebral endplates erosions > 50\% & $16(37.2)$ & $9(28.1)$ & 0.41 \\
\hline Paravertebral infiltration $\geq 10 \mathrm{~mm}$ & $22(52.4)$ & $4(13.3)$ & 0.0006 \\
\hline \multicolumn{4}{|l|}{ Spine Level, n (\%) } \\
\hline Cervical & $3(5.7)$ & $2(5.7)$ & 1.0 \\
\hline Thoracic & $20(37.7)$ & $12(34.3)$ & 0.7 \\
\hline Lumbar & $30(56.6)$ & $21(60.0)$ & 0.8 \\
\hline \multicolumn{4}{|l|}{ Microbiology, n (\%) } \\
\hline Monomicrobial infection & $41(77.4)$ & NA & NA \\
\hline Coagulase negative staphylococci & $15(28.3)$ & NA & NA \\
\hline Staphylococcus aureus & $10(18.9)$ & NA & NA \\
\hline Cutibacterium acnes & $7(13.2)$ & NA & NA \\
\hline Escherichia coli & $3(5.7)$ & NA & NA \\
\hline Streptococci & $4(7.5)$ & NA & NA \\
\hline Anaerobes & $3(5.7)$ & NA & NA \\
\hline Pseudomonas aeruginosa & $2(3.8)$ & NA & NA \\
\hline Enterococci & $1(1.9)$ & NA & NA \\
\hline Klebsiella spp. & $1(1.9)$ & NA & NA \\
\hline
\end{tabular}

ALP Alkaline phosphatase, CRP C-reactive protein, DVB Disco-vertebral biopsy, IQR Interquartile range, NA Not applicable, NS Not significant, PVO Pyogenic vertebral osteomyelitis, WBC White cell blood 
Table 2 Positive rate of disco-vertebral biopsies (DVB) cultures according to modality of guidance and spine level

\begin{tabular}{llll}
\hline & $\begin{array}{l}\text { Fluoroscopic } \\
\text { Guidance }\end{array}$ & $\begin{array}{l}\text { Scanographic } \\
\text { guidance }\end{array}$ & $\boldsymbol{P}$-value \\
\hline All spine levels & $34 / 51$ & $19 / 37$ & 0.15 \\
Cervical level & $3 / 4$ & $0 / 1$ & 0.4 \\
Thoracic level & $6 / 11$ & $14 / 21$ & 0.7 \\
Lumbar level & $25 / 36$ & $5 / 15$ & 0.02 \\
\hline
\end{tabular}

needle position [23]. Regarding the L5-S1 space, fluoroscopic guidance is almost systematic because the disk is very recessed. Indeed, DVB at this level need a larger craniocaudal angulation, which is impossible under scanographic guidance.

Nevertheless, no significant difference between fluoroscopic guidance and scanographic guidance had been shown at other level, which could be due to the small sample size [14, 17, 24].

This original finding was not found in a previous meta-analysis, which did not show any statistically significant difference between fluoroscopic and scanographic guidance of DVB concerning their accuracy [25]. Our results could be due to the expertise of our hospital, which is a referral center for bone and joint infections. Moreover, the high rate of positive microbiological diagnosis in our cohort is probably due to the microbiological analysis procedure of the sample which is optimal (Table 3) $[8,15,16]$.

No biopsy-related complications were recorded.

One could deplore a lack of information concerning the quality of the biopsy specimen such as the number of samples or the size of the needle used to perform DVB or aspiration of purulent fluid during DVB, which is limited due to the retrospective design. However, several authors did not show any significant difference concerning the needle type and his diameter in terms of diagnostic rate $[8,12,15$, 23].

Limitations of the study include its retrospective study design, which may have resulted in missing key variables; there is possibility of selection bias. In addition, our sample size may not be large enough to detect other significant predictive factors of positivity. But, PVO is a rare condition, so it is difficult to perform a prospective study with a large sample of patients and the same DVB technique.

Table 3 Meta-analysis concerning the diagnostic yield of disco-vertebral biopsy for pyogenic vertebral osteomyelitis

\begin{tabular}{|c|c|c|c|c|c|}
\hline References & Number of patients included & Type of study & & Study of predictive positive factors of DVB & $\%$ of positive DVB \\
\hline Osenbach 1990 [26] & 40 & Retrospective & Multicentric & No & $90 \%(36 / 40)$ \\
\hline Bontoux 1992 [27] & 82 & Retrospective & Monocentric & No & $47.5 \%(19 / 40)$ \\
\hline Perronne 1994 [28] & 39 & Retrospective & Monocentric & No & $74 \%(29 / 39)$ \\
\hline Torda 1995 [29] & 15 & Retrospective & Monocentric & No & $73 \%(11 / 15)$ \\
\hline Fouquet 1996 [30] & 67 & Retrospective & Monocentric & No & $51 \%(34 / 67)$ \\
\hline Rieneck 1996 [31] & 14 & Retrospective & Monocentric & No & $57 \%(8 / 14)$ \\
\hline Honan 1996 [32] & 12 & Retrospective & Monocentric & No & $83 \%(10 / 12)$ \\
\hline Carragee 1997 [33] & 44 & Retrospective & Monocentric & No & $61 \%(27 / 44)$ \\
\hline Jensen 1998 [34] & 133 & Retrospective & Multicentric & No & $40 \%(53 / 133)$ \\
\hline Hadjipavlou 2000 [35] & 21 & Prospective & Monocentric & No & $57 \%(12 / 21)$ \\
\hline Lucio 2000 [25] & 20 & Retrospective & Monocentric & No & $75 \%(15 / 20)$ \\
\hline Chew 2001 [3] & 43 & Retrospective & Multicentric & No & $91 \%(39 / 43)$ \\
\hline Ben Taarit 2002 [36] & 21 & Retrospective & Monocentric & No & $48 \%(10 / 21)$ \\
\hline Mc Henry 2002 [7] & $253^{\mathrm{a}}$ & Retrospective & Multicentric & No & $69 \%(86 / 124)$ \\
\hline Nolla 2002 [37] & 21 & Retrospective & Monocentric & No & $52 \%(11 / 21)$ \\
\hline Cherasse 2003 [38] & 35 & Retrospective & Monocentric & No & $69 \%(24 / 35)$ \\
\hline Rankine 2004 [24] & 20 & Retrospective & Monocentric & No & $40 \%(8 / 20)$ \\
\hline Mylona 2008 [22] & NA & NA & NA & No & $79 \%$ \\
\hline D'agostino 2010 [39] & 81 & Retrospective & Monocentric & No & $76 \%(62 / 81)$ \\
\hline Rio 2014 [40] & 58 & Retrospective & Monocentric & No & $64 \%(37 / 58)$ \\
\hline Gras 2014 [13] & 136 & Retrospective & Multicentric & Yes & $43 \%(59 / 136)$ \\
\hline
\end{tabular}

DVB Disco-vertebral biopsy, NA Not available

${ }^{\text {aAmong }}$ the 253 included patients, 124 patients received PVB 


\section{Conclusion}

Fluoroscopic guidance of DVB seems to be better than scanographic guidance at the lumbar spine level. It is an accurate method for identifying the microorganism involved in PVO, in order to properly manage this disease. It is a safe and well-tolerated procedure. We demonstrated that a paravertebral thickening $\geq 10 \mathrm{~mm}$ is a predictive positive factor for DVB.

\section{Abbreviations}

Cl: Confidence interval; DVB: Disco-vertebral biopsy; IQR: Interquartile range; MIC: Minimal inhibitory concentration; MRI: Magnetic resonance imaging; OR: Odds ratio; PVO: Pyogenic vertebral osteomyelitis

\section{Acknowledgements}

The authors would like to thank Elodie Choisy for her help in this study.

\section{Authors' contributions}

$A D$ and RYC were involved in the conception and design of the work. CD1, CJ, and RYC were involved in the radiological data acquisition. CD1 and CD2 were involved in the clinical data acquisition. $A L R, L N$, and $M R$ were involved in the collection of microbiological data and analysis. CD1, CJ, CD2, and AD were involved in the analysis or interpretation of data for the work. CD1 and $A D$ wrote the first draft of the manuscript. All authors were involved in drafting the work and revising it critically. The authors gave final approval of the version to be published.

\section{Funding}

None.

\section{Availability of data and materials}

The datasets used and/or analysed during the current study are available from the corresponding author on reasonable request.

\section{Ethics approval and consent to participate}

Considering the retrospective study design, data collection from preexisting medical records, and respect for the anonymity of the patients included (referred to as studies "Hors Loi Jardé" in France), no ethical approval or administrative approval were necessary for this study. This study was submitted to the local Data Protection Officer (DPO), and upon approval, identified in the hospital study registry.

\section{Consent for publication}

Not applicable.

\section{Competing interests}

None to declare.

\section{Author details}

${ }^{1}$ Department of medical imaging, Raymond Poincaré University Hospital, AP-HP Paris Saclay University, 92380 Garches, France. ${ }^{2}$ Microbiology laboratory, Raymond Poincaré University Hospital, AP-HP Paris Saclay University, 92380 Garches, France. ${ }^{3}$ Infectious disease unit, Raymond Poincaré University Hospital, AP-HP Paris Saclay University, 104, boulevard Raymond Poincaré, 92380 Garches, France.

\section{Received: 22 March 2020 Accepted: 2 July 2020}

Published online: 16 July 2020

\section{References}

1. Diehn FE. Imaging of spine infection. Radiol Clin North Am. 2012;50:777-98.

2. Gouliouris T, Aliyu SH, Brown NM. Spondylodiscitis: update on diagnosis and management. J Antimicrob Chemother. 2010;65 Suppl 3:iii11-24.

3. Chew FS, Kline MJ. Diagnostic yield of CT-guided percutaneous aspiration procedures in suspected spontaneous infectious diskitis. Radiology. 2001; 218:211-4.

4. Berbari EF, Kanj SS, Kowalski TJ, Darouiche RO, Widmer AF, Schmitt SK, et al. 2015 Infectious Diseases Society of America (IDSA) clinical practice guidelines for the diagnosis and treatment of native vertebral osteomyelitis in adults. Clin Infect Dis. 2015;61:859-63.

5. Wirtz DC, Genius I, Wildberger JE, Adam G, Zilkens KW, Niethard FU. Diagnostic and therapeutic management of lumbar and thoracic spondylodiscitis--an evaluation of 59 cases. Arch Orthop Trauma Surg. 2000; 120:245-51.

6. Friedman JA, Maher CO, Quast LM, McClelland RL, Ebersold MJ. Spontaneous disc space infections in adults. Surg Neurol. 2002;57:81-6.

7. McHenry MC, Easley KA, Locker GA. Vertebral osteomyelitis: long-term outcome for 253 patients from 7 Cleveland-area hospitals. Clin Infect Dis. 2002;34:1342-50.

8. Société de Pathologie Infectieuse de Langue Française (SPILF). [recommendations for clinical practice - infectious spondylodiscitis] [in French]; 2007. https:/www.infectiologie.com/UserFiles/File/medias/_documents/ consensus/2007-Spondylodiscites-Reco.pdf. Accessed 10 Feb 2020.

9. Jean M, Irisson J-O, Gras G, Bouchand F, Simo D, Duran C, et al. Diagnostic delay of pyogenic vertebral osteomyelitis and its associated factors. Scand J Rheumatol. 2017:46:64-8

10. Renfrew DL, Whitten CG, Wiese JA, El- Khoury GY, Harris KG. CT-guided percutaneous transpedicular biopsy of the spine. Radiology. 1991;180:574-6.

11. Heyer CM, Brus L-J, Peters SA, Lemburg SP. Efficacy of CT-guided biopsies of the spine in patients with spondylitis--an analysis of 164 procedures. Eur J Radiol. 2012;81:e244-9.

12. Sucu HK, Ciçek C, Rezanko T, Bezircioğlu H, Erşahin Y, Tunakan M, et al. Percutaneous computed-tomography-guided biopsy of the spine: 229 procedures. Joint Bone Spine. 2006;73:532-7.

13. Gras G, Buzele R, Parienti JJ, Debiais F, Dinh A, Dupon M, et al. Microbiological diagnosis of vertebral osteomyelitis: relevance of second percutaneous biopsy following initial negative biopsy and limited yield of post-biopsy blood cultures. Eur J Clin Microbiol Infect Dis. 2014;33:371-5.

14. Enoch DA, Cargill JS, Laing R, Herbert S, Corrah TW, Brown NM. Value of CTguided biopsy in the diagnosis of septic discitis. J Clin Pathol. 2008;61:750-3.

15. Wu JS, Gorbachova T, Morrison WB, Haims AH. Imaging-guided bone biopsy for osteomyelitis: are there factors associated with positive or negative cultures? AJR Am J Roentgenol. 2007;188:1529-34.

16. Grammatico L, Baron S, Rusch E, Lepage B, Surer N, Desenclos JC, et al. Epidemiology of vertebral osteomyelitis (VO) in France: analysis of hospitaldischarge data 2002-2003. Epidemiol Infect. 2008;136:653-60.

17. Kim BJ, Lee JW, Kim SJ, Lee GY, Kang HS. Diagnostic yield of fluoroscopyguided biopsy for infectious spondylitis. AJNR Am J Neuroradiol. 2013;34: 233-8.

18. Roux A-L, Sivadon-Tardy V, Bauer T, Lortat-Jacob A, Herrmann J-L, Gaillard J$L$, et al. Diagnosis of prosthetic joint infection by beadmill processing of a periprosthetic specimen. Clin Microbiol Infect. 2011;17:447-50. https://doi. org/10.1111/j.1469-0691.2010.03359.x.

19. European Committee on Antimicrobial Susceptibility Testing (EUCAST). EUCAST: clinical breakpoints; 2018. http://www.eucast.org/clinical_ breakpoints/. Accessed 7 Sep 2018.

20. Sehn JK, Gilula LA. Percutaneous needle biopsy in diagnosis and identification of causative organisms in cases of suspected vertebral osteomyelitis. Eur J Radiol. 2012;81:940-6.

21. Nourbakhsh A, Grady JJ, Garges KJ. Percutaneous spine biopsy: a metaanalysis. J Bone Joint Surg Am. 2008;90:1722-5.

22. Mylona E, Samarkos M, Kakalou E, Fanourgiakis P, Skoutelis A. Pyogenic vertebral osteomyelitis: a systematic review of clinical characteristics. Semin Arthritis Rheum. 2009;39:10-7.

23. Chang CY, Simeone FJ, Nelson SB, Taneja AK, Huang AJ. Is Biopsying the paravertebral soft tissue as effective as Biopsying the disk or vertebral endplate? 10-year retrospective review of CT-guided biopsy of diskitisosteomyelitis. AJR Am J Roentgenol. 2015;205:123-9.

24. Rankine JJ, Barron DA, Robinson P, Millner PA, Dickson RA. Therapeutic impact of percutaneous spinal biopsy in spinal infection. Postgrad Med J. 2004;80:607-9.

25. Lucio E, Adesokan A, Hadjipavlou AG, Crow WN, Adegboyega PA. Pyogenic spondylodiskitis: a radiologic/pathologic and culture correlation study. Arch Pathol Lab Med. 2000;124:712-6.

26. Osenbach RK, Hitchon PW, Menezes AH. Diagnosis and management of pyogenic vertebral osteomyelitis in adults. Surg Neurol. 1990;33:266-75.

27. Bontoux D, Codello L, Debiais F, Lambert de Cursay G, Azais I, Alcalay M. Infectious spondylodiscitis. Analysis of a series of 105 cases. Rev Rhum Mal Osteoartic. 1992;59:401-7. 
28. Perronne C, Saba J, Behloul Z, Salmon-Céron D, Leport C, Vildé JL, et al. Pyogenic and tuberculous spondylodiskitis (vertebral osteomyelitis) in 80 adult patients. Clin Infect Dis An Off Publ Infect Dis Soc Am. 1994;19:746-50.

29. Torda AJ, Gottlieb T, Bradbury R. Pyogenic vertebral osteomyelitis: analysis of 20 cases and review. Clin Infect Dis An Off Publ Infect Dis Soc Am. 1995; 20:320-8.

30. Fouquet B, Goupille P, Gobert F, Cotty P, Roulot B, Valat JP. Infectious discitis diagnostic contribution of laboratory tests and percutaneous discovertebral biopsy. Rev Rhum Engl Ed. 1996;63:24-9.

31. Rieneck K, Hansen SE, Karle A, Gutschik E. Microbiologically verified diagnosis of infectious spondylitis using CT-guided fine needle biopsy. APMI S Acta Pathol Microbiol Immunol Scand. 1996;104:755-62.

32. Honan M, White GW, Eisenberg GM. Spontaneous infectious discitis in adults. Am J Med. 1996;100:85-9.

33. Carragee EJ. Pyogenic vertebral osteomyelitis. J Bone Joint Surg Am. 1997: 79:874-80.

34. Jensen AG, Espersen F, Skinhøj P, Frimodt-Møller N. Bacteremic Staphylococcus aureus spondylitis. Arch Intern Med. 1998;158:509-17.

35. Hadjipavlou AG, Mader JT, Necessary JT, Muffoletto AJ. Hematogenous pyogenic spinal infections and their surgical management. Spine (Phila Pa 1976). 2000;25:1668-79.

36. Ben Taarit C, Turki S, Ben MH. Infectious spondylitis. Study of a series of 151 cases. Acta Orthop Belg. 2002;68:381-7.

37. Nolla JM, Ariza J, Gómez-Vaquero C, Fiter J, Bermejo J, Valverde J, et al. Spontaneous pyogenic vertebral osteomyelitis in nondrug users. Semin Arthritis Rheum. 2002;31:271-8

38. Cherasse A, Martin D, Tavernier C, Maillefert JF. Are blood cultures performed after disco-vertebral biopsy useful in patients with pyogenic infective spondylitis? Rheumatology (Oxford). 2003;42:913.

39. D'Agostino C, Scorzolini L, Massetti AP, Carnevalini M, d'Ettorre G, Venditti $M$, et al. A seven-year prospective study on spondylodiscitis: epidemiological and microbiological features. Infection. 2010;38:102-7.

40. Rio S, Marcelli C. Analyses comparatives de l'efficience de la ponctionbiopsie disco-vertébrale dans l'établissement du diagnostic bactériologique des spondylodiscites infectieuses non tuberculeuses. Rev Rhum. 2014;81: $333-5$.

\section{Publisher's Note}

Springer Nature remains neutral with regard to jurisdictional claims in published maps and institutional affiliations.

Ready to submit your research? Choose BMC and benefit from:

- fast, convenient online submission

- thorough peer review by experienced researchers in your field

- rapid publication on acceptance

- support for research data, including large and complex data types

- gold Open Access which fosters wider collaboration and increased citations

- maximum visibility for your research: over $100 \mathrm{M}$ website views per year

At $\mathrm{BMC}$, research is always in progress.

Learn more biomedcentral.com/submissions 